\title{
A Spatial Panel Ordered-Response Model with Application to the Analysis of Urban Land Use Development Intensity Patterns
}

\author{
Nazneen Ferdous \\ Resource Systems Group, Inc. \\ 55 Railroad Row, White River Junction, VT 05001 \\ Phone: 802-295-4999, Fax: 802-295-1006 \\ E-mail: nazneen.ferdous@utexas.edu
}

and

Chandra R. Bhat*

The University of Texas at Austin

Dept of Civil, Architectural \& Environmental Engineering

1 University Station C1761, Austin TX 78712-0278

Phone: 512-471-4535, Fax: 512-475-8744

E-mail: bhat@mail.utexas.edu

*corresponding author

February 29, 2012 


\begin{abstract}
This paper proposes and estimates a spatial panel ordered-response probit model with temporal autoregressive error terms to analyze changes in urban land development intensity levels over time. Such a model structure maintains a close linkage between the land owner's decision (unobserved to the analyst) and the land development intensity level (observed by the analyst), and accommodates spatial interactions between land owners that lead to spatial spillover effects. In addition, the model structure incorporates spatial heterogeneity as well as spatial heteroscedasticity. The resulting model is estimated using a composite marginal likelihood (CML) approach that does not require any simulation machinery and that can be applied to data sets of any size. A simulation exercise indicates that the CML approach recovers the model parameters very well, even in the presence of high spatial and temporal dependence. In addition, the simulation results demonstrate that ignoring spatial dependency and spatial heterogeneity when both are actually present will lead to bias in parameter estimation. A demonstration exercise applies the proposed model to examine urban land development intensity levels using parcel-level data from Austin, Texas.
\end{abstract}

Keywords: $\quad$ Spatial econometrics, panel data, random coefficients, urban land development intensity, composite marginal likelihood (CML) approach. 


\section{INTRODUCTION}

\subsection{Background and Motivation}

There is increasing interest and attention on recognizing and explicitly accommodating spatial dependence among decision-makers in models of continuous and discrete choices. While specification and modeling considerations related to spatial dependence appear to have originated initially in urban and regional modeling, such considerations have now permeated into economics and mainstream social sciences, including agricultural and natural resource economics, public economics, geography, sociology, political science, and epidemiology. The reader is referred to a special issue of Regional Science and Urban Economics, edited by Arbia and Kelejian (2010), for a collection of recent papers on spatial dependence, and to Elhorst (2009) and Lee and Yu (2010) for good reviews of recent research on spatial panel data models. Anselin (2010), Brady and Irwin (2011), and Anselin et al. (2008) are additional resources for overviews of the developments in the spatial econometrics field.

At the same time that spatial considerations are receiving widespread attention, a specific kind of discrete choice structure - the ordered-response multinomial structure - has also seen a literal explosion in application in many different disciplines, including sociology, biology, political science, marketing, and transportation sciences. Ordered-response models may be used when analyzing ordinal discrete outcome data, including ratings data (for instance, of consumer products and movies), or likert-scale type attitudinal/opinion data (for example, of traffic congestion levels and teacher evaluations), or intensity data (such as of land use development levels and pain levels). In all of these situations, the observed outcome data may be considered to be the result of the partitioning or thresholding of an underlying latent continuous variable into mutually exclusive (non-overlapping) intervals. Some recent examples of the use of orderedresponse structures include examining crash severity (Quddus et al., 2010), analyzing job satisfaction (Luechinger, et al., 2010), studying trip generation (Roorda et al., 2010), and examining monetary policies of a bank (Xiong, 2011). The reader is referred to Greene and Hensher (2010) for a comprehensive history and review of the ordered-response model structure.

It should be clear from above that both spatial dependencies as well as ordered-response structures are becoming common place in the tool box of researchers in a wide variety of disciplines. However, there has been little research at the interface of spatial dependence and ordered-response structures. In particular, much of the literature on spatial dependency has been 
confined to the case of continuous dependent variables (and not discrete dependent variables), while much of the ordered-response literature has focused on the case of a (non-spatial) univariate ordered-response system. Of course, in the past decade, spatial dependence structures developed in the context of continuous dependent variables are increasingly being considered for binary discrete choice dependent variables (see Franzese et al., 2010 and Bhat and Sener, 2009 for good reviews). The two dominant techniques, both based on simulation methods, for the estimation of such spatial binary discrete models are the frequentist recursive importance sampling (RIS) estimator (see Beron et al., 2003 and Beron and Vijverberg, 2004) and the Bayesian Markov Chain Monte Carlo (MCMC)-based estimator (see Kakamu and Wago 2007 and LeSage and Pace, 2009). Such methods may be extended to ordered-response structures in a relatively straightforward manner. However, both the RIS and MCMC-based methods are confronted with multi-dimensional normal integration (of the order of the number of observations in the estimation sample when using the general flexible spatial dependence forms adopted for continuous models), and are therefore computationally expensive-to-infeasible to implement (for both binary and ordered-response structures) with the typical computational resources at hand for anything other than small sample sizes (see Bhat, 2011, Smironov, 2010, and Franzese et al., 2010).

In contrast to the extant simulation-based inference procedures discussed above, an approach that has seen some (though very limited) use recently in the context of (non-spatial) multivariate binary and ordered-response models is the composite marginal likelihood (CML) approach. This is an estimation technique that is gaining substantial attention in the statistics field, though there has been relatively little coverage of this method in econometrics and other fields. The CML method, which belongs to the more general class of composite likelihood function approaches, is based on forming a surrogate likelihood function that compounds much easier-to-compute, lower-dimensional, marginal likelihoods. The CML method is easy to implement and has the advantage of reproducibility of results. Under usual regularity assumptions, the CML estimator is consistent and asymptotically normal distributed. Thus, the CML is an appealing inference approach when traditional simulation methods become computationally cumbersome or even intractable. Recent studies that use this approach for nonspatial multivariate binary/ordered-response modeling include Yi et al., 2011, Varin and Czado 2010, Ferdous et al., 2010, and Bhat et al., 2010a. 


\subsection{The Current Paper}

The methodological focus of the current paper is to develop a formulation for a spatial panel ordered-response model and propose a practical composite marginal likelihood (CML) inference approach to obtain model parameter estimates. Spatial dependence is introduced through contemporaneous "spillover" effects in both the exogenous variables as well as the error terms, using a spatial lag specification on the latent variables of decision-makers (that underlie the observed ordinal variables of decision-makers). Such a specification recognizes that spatial dependence is a substantive issue, and is caused by didactic interactions among decision-making agents (as opposed to considering spatial dependence only in the error terms, which is tantamount to viewing spatial dependence as "nuisance" dependence). In addition to spatial dependence, we incorporate (unobserved) spatial heterogeneity by allowing the sensitivity to exogenous variables to vary across decision-makers. This is achieved through the use of an individual-specific, time-stationary, random coefficients formulation for the latent variables. Finally, we also accommodate time-varying dependency effects across the latent variables of the same agent at different points in time.

The empirical focus of the current paper is on using the spatial lag specification to examine the land development intensity levels of spatial units, recognizing the spatial dependence in the development intensities of proximately located spatial units due to interactions between land owners of the corresponding spatial units. Such interactions should naturally arise because land owners of proximately located spatial units (say, parcels), acting as profitmaximizing economic agents, are likely to be influenced by each other's perceptions of net stream of returns from land use development. The peer influences may also be due to strategic or collaborative partnerships between land owners (see, for example, Carrión-Flores et al., 2009). The net result is that changes in observed variables (such as accessibility to the city-center) and/or unobserved variables (such as neighborhood politics and zoning guidelines) that affect the land use development returns (LUDR) perception of one land owner will also likely lead to a shift in the LUDR perception of land owners of neighboring parcels. At the same time, spatial heterogeneity can arise in the land development context because different land owners may have different intrinsic LUDR perceptions and may respond differently to the exogenous variables, based on such unobserved factors as individual experiences, risk-taking behavior, and even vegetation conservation values. Such land owner-specific random coefficients and resulting 
temporal correlations of the land owner's choices across time have been ignored thus far in the literature. Finally, we also accommodate time-varying dependency effects across the LUDR perceptions of the same decision agent at different points in time, which may be attributed to the effects of recent experiences and events that may influence the risk-taking or risk-averseness or other LUDR-related perceptions of individual land owners. As such, these effects fade over time.

In this paper, we first formulate the spatial panel ordered-response model, next propose a CML inference procedure, and then undertake simulation experiments to examine the ability of the inference procedure to recover underlying model parameters. Subsequently, we demonstrate the applicability of the proposed formulation and inference procedure by modeling urban land use development intensity patterns in Austin, Texas, using data from the years 2000, 2003, 2006, and 2008. The land use information used in the current empirical analysis is available at a parcellevel spatial resolution. While various different levels and thresholds may be employed to define the intensity level of land development, we adopt a four category ordinal system: (1) undeveloped land (open space, vacant parcel, etc.), (2) less-intensely developed land (residential parcels with single-family detached or two-family attached home), (3) medium-intensely developed land (includes all other types of residential parcels), and (4) most-intensely developed land (includes office, commercial, industrial parcels, etc.). The data set comprises 783 parcels from each of the four years.

The rest of the paper is structured as follows. Section 2 discusses the model structure and

the estimation approach, Section 3 presents a simulation study to evaluate the ability of our proposed approach to recover model parameters and also demonstrates the effects of ignoring spatial dependency and spatial heterogeneity when they are actually present. Section 4 describes the data sources and sample formation procedures for the Austin data sample used in this paper. Section 5 presents the empirical results and elasticity effects. The final section summarizes the important findings from the study and concludes the paper.

\section{THE MODEL}

\subsection{Basic Formulation}

Let $q$ be an index for spatial units $(q=1,2, \ldots, Q$, where $Q$ denotes the total number of spatial units/parcels in the data set), and let $t$ be an index for time period $(t=1,2, \ldots, T$, where $T$ is the 
number of panel observations for each spatial unit; in the current paper, $T=4) .{ }^{1}$ Let $l$ be an index for the observed land use development category, which may take one of $L$ discrete ordinal values (i.e., $l \in\{1,2, \ldots, L\}$ ). Assume that the land use development returns (LUDR) perception of the land owner of the $q^{t h}$ parcel at time $t$ is $y_{q t}^{*}$ (in the rest of this section, we will use the term "parcel" to refer to the spatial unit of analysis, though any other spatial unit may be used depending on the nature of the analysis). The LUDR perception is not observed by the analyst. But, in the usual ordered-response framework, we write this latent perception $\left(y_{q t}^{*}\right)$ as a function of relevant covariates, and relate this latent propensity to the observed land use $l$ through threshold bounds as follows (see McKelvey and Zavoina, 1975):

$$
y_{q t}^{*}=\delta \sum_{q^{\prime}=1}^{Q} w_{q q^{\prime}} y_{q^{\prime} t}^{*}+\boldsymbol{\beta}_{\mathbf{q}}^{\prime} \mathbf{x}_{\mathbf{q t}}+\varepsilon_{q t}, y_{q t}=l \text { if } \psi_{l-1}<y_{q t}^{*}<\psi_{l}, \boldsymbol{\beta}_{\mathbf{q}}=\mathbf{b}+\widetilde{\boldsymbol{\beta}}_{\mathbf{q}},
$$

The basic idea of the ordered-response formulation is that land owners with a low LUDR perception will keep their land undeveloped, while land owners with a high LUDR perception will invest their land in intense land use development. In the above equation, the first term reflects the spatial lag structure, where $w_{q q^{\prime}}$ is the spatial proximity-based weight corresponding to units $q$ and $q^{\prime}$ (with $w_{q q}=0$ and $\sum_{q^{\prime}} w_{q q^{\prime}}=1$ ) for each (and all) $q$, and $\delta(0<\delta<1)$ is the spatial autoregressive parameter. $\mathbf{x}_{\mathbf{q t}}$ is a $(K \times 1)$ vector of exogenous variables corresponding to parcel $q$ and time period $t$ ( $\mathbf{x}_{\mathbf{q t}}$ includes a constant), $\boldsymbol{\beta}_{\mathbf{q}}$ is a corresponding $(K \times 1)$ vector of random coefficients that is $K$-dimensional multivariate normal $\left(M V N_{K}\right)$. For later use, we will partition $\boldsymbol{\beta}_{\mathbf{q}}$ into a $(K \times 1)$ mean vector $\mathbf{b}$ and a $(K \times 1)$ random component $\widetilde{\boldsymbol{\beta}}_{\mathbf{q}}$ with mean zero and variance $\boldsymbol{\Omega}=\mathbf{L} \mathbf{L}^{\prime}$ (i.e., $\widetilde{\boldsymbol{\beta}}_{\mathbf{q}} \sim \operatorname{MVN}_{\mathrm{K}}[\mathbf{0}, \boldsymbol{\Omega}]$ ). It is not necessary that all elements of $\boldsymbol{\beta}_{\mathbf{q}}$ be random; that is, the analyst may specify fixed coefficients on some exogenous variables in the model, though it will be convenient in presentation to assume that all elements of $\boldsymbol{\beta}_{\mathbf{q}}$ are random. Also, note that the element of $\mathbf{b}$ corresponding to the constant is fixed to zero for identification. The upper bound threshold for ordinal level $l$ is represented by $\psi_{l}$

\footnotetext{
${ }^{1}$ In the empirical context of the current paper, the number of panel observations is the same across spatial units, i.e., the data set is a balanced panel. However, the methodology in this paper is generic and equally applicable to unbalanced panels.
} 
$\left(\psi_{0}<\psi_{1}<\psi_{2} \ldots<\psi_{L-1}<\psi_{L} ; \psi_{0}=-\infty\right.$ and $\left.\psi_{L}=+\infty\right)$. The term $\varepsilon_{q t}$ in the above equation is a standard normal error term uncorrelated across parcels for a particular time period $t$. However, we allow a first-order autoregressive correlation pattern within each spatial unit-specific series of observations so that $\operatorname{Cov}\left(\varepsilon_{q t}, \varepsilon_{q t^{\prime}}\right)=\rho^{\left|t^{\prime}-t\right|}(0<\rho<1)$.

The formulation above generates spatial dependence through the spatial lag term, the nature of which is related to the specification of the weight terms $w_{q q^{\prime}}$. This can take the form of a discrete function such as a contiguity specification $\left(w_{q q^{\prime}}=1\right.$ if the parcels $q$ and $q^{\prime}$ are adjacent and 0 otherwise) or a specification based on a distance threshold $\left(w_{q q^{\prime}}=c_{q q^{\prime}} / \sum_{q^{\prime}} c_{q q^{\prime}}\right.$, where $c_{q q^{\prime}}$ is a dummy variable taking the value 1 if the parcel $q^{\prime}$ is within the distance threshold and 0 otherwise). It can also take a continuous form such as those based on the inverse of distance $d_{q q^{\prime}}$ and its power functions $\left(w_{q q^{\prime}}=\left(1 / d_{q q^{\prime}}^{n}\right)\left[\sum_{q^{\prime}} 1 / d_{q q^{\prime}}^{n}\right]^{-1}\right)(n>0)$, the inverse of exponential distance, and the shared border length $\widetilde{d}_{q q^{\prime}}$ between parcels $w_{q q^{\prime}}=\widetilde{c}_{q q^{\prime}} \widetilde{d}_{q q^{\prime}} /\left(\sum_{q^{\prime}} \widetilde{c}_{q q^{\prime}} \widetilde{d}_{q q^{\prime}}\right.$, (where $\widetilde{c}_{q q^{\prime}}$ is a dummy variable taking the value 1 if the parcels $q$ and $q^{\prime}$ are adjoining, and 0 otherwise). All of these functional forms for the weight matrix may be tested empirically. In addition to spatial dependence, the random coefficient vector $\boldsymbol{\beta}_{\mathbf{q}}$ accommodates spatial heterogeneity as well as implicitly generates spatial heteroscedasticity. Note that we are able to disentangle spatial dependence and spatial heterogeneity because of the availability of panel data. Further, the vector $\boldsymbol{\beta}_{\mathbf{q}}$ generates time-invariant temporal dependence effects in the LUDR perceptions of the same land owner.

Several restrictive models are obtained from the model developed here. If $\rho=0$, this indicates lack of time-varying temporal correlation. If $\delta=0$, the result is a non-spatial model. If the elements of $\boldsymbol{\Omega}$ are zero, the indication is the lack of time-invariant temporal effects as well as unobserved spatial heterogeneity. If the elements of $\boldsymbol{\Omega}$ corresponding to the non-diagonal elements of $\boldsymbol{\Omega}$ are zero, but not the diagonal elements, it represents the case of the presence of time-invariant and unobserved heterogeneity effects, but without correlation between these 
effects. If the elements of $\boldsymbol{\Omega}$ except for that corresponding to the constant are collectively zero, the model collapses to a random-effects structure. If $\rho=0, \delta=0$, and all elements of $\boldsymbol{\Omega}$ are identically zero, the result is a standard ordered-response model.

\subsection{Matrix Formulation}

The model proposed above may be written in a more compact form to facilitate the discussion of the estimation technique. To do so, we define the following vectors and matrices:

$$
\begin{aligned}
& \mathbf{y}_{\mathbf{t}}^{*}=\left(y_{1 t}^{*}, y_{2 t}^{*}, y_{3 t}^{*}, \ldots, y_{Q t}^{*}\right)^{\prime}(Q \times 1 \text { matrix }), \\
& \mathbf{y}^{*}=\left[\left(\mathbf{y}_{1}^{*}\right)^{\prime},\left(\mathbf{y}_{2}^{*}\right)^{\prime},\left(\mathbf{y}_{3}^{*}\right)^{\prime}, \ldots,\left(\mathbf{y}_{\mathbf{T}}^{*}\right)^{\prime}\right]^{\prime} \quad(Q T \times 1 \text { matrix }), \\
& \boldsymbol{\varepsilon}_{\mathrm{t}}=\left(\varepsilon_{1 t}, \varepsilon_{2 t}, \varepsilon_{3 t}, \ldots, \varepsilon_{Q t}\right)^{\prime}(Q \times 1 \text { matrix }), \\
& \varepsilon=\left(\varepsilon_{1}^{\prime}, \varepsilon_{2}^{\prime}, \varepsilon_{3}^{\prime}, \ldots, \varepsilon_{\mathrm{T}}^{\prime}\right)^{\prime}(Q T \times 1 \text { matrix }), \\
& \mathbf{x}_{\mathbf{q t}}=\left(x_{q t 1}, x_{q t 2}, x_{q t 3}, \ldots, x_{q t K}\right)^{\prime}(K \times 1 \text { matrix }), \\
& \mathbf{x}_{\mathbf{t}}=\left(\mathbf{x}_{1 \mathrm{t}}, \mathbf{x}_{2 \mathrm{t}}, \mathbf{x}_{3 \mathrm{t}}, \ldots, \mathbf{x}_{\mathbf{Q t}}\right)^{\prime}(Q \times K \text { matrix }), \\
& \mathbf{x}=\left(\mathbf{x}_{1}^{\prime}, \mathbf{x}_{2}^{\prime}, \mathbf{x}_{3}^{\prime}, \ldots, \mathbf{x}_{\mathbf{T}}^{\prime}\right)^{\prime}(Q T \times K \text { matrix }), \\
& \widetilde{\mathbf{x}}_{\mathbf{t}}=\left[\begin{array}{ccccc}
\mathbf{x}_{1 \mathbf{t}}^{\prime} & 0 & 0 & \cdots & 0 \\
0 & \mathbf{x}_{\mathbf{2 t}}^{\prime} & 0 & \cdots & 0 \\
0 & 0 & \mathbf{x}_{\mathbf{3 t}}^{\prime} & \cdots & 0 \\
\vdots & \vdots & \vdots & \ddots & \vdots \\
0 & 0 & 0 & \cdots & \mathbf{x}_{\mathbf{Q t}}^{\prime}
\end{array}\right](Q \times K Q \text { block diagonal matrix }) \\
& \widetilde{\mathbf{x}}=\left(\widetilde{\mathbf{x}}_{1}^{\prime}, \widetilde{\mathbf{x}}_{\mathbf{2}}^{\prime}, \widetilde{\mathbf{x}}_{3}^{\prime}, \ldots, \widetilde{\mathbf{x}}_{\mathbf{T}}^{\prime}\right)^{\prime} \quad(Q T \times K Q \text { matrix }), \\
& \widetilde{\boldsymbol{\beta}}=\left(\widetilde{\boldsymbol{\beta}}_{1}^{\prime}, \widetilde{\boldsymbol{\beta}}_{2}^{\prime}, \widetilde{\boldsymbol{\beta}}_{3}^{\prime}, \ldots, \widetilde{\boldsymbol{\beta}}_{\mathbf{Q}}^{\prime}\right)^{\prime} \quad(K Q \times 1 \text { matrix }) .
\end{aligned}
$$

Also, collect all the weights $w_{q q^{\prime}}$ into a spatial weight matrix $\mathbf{W}$. The vector $\widetilde{\boldsymbol{\beta}}$ above has a mean vector of zero and a variance matrix $\mathbf{I}_{\mathbf{Q}} \otimes \mathbf{\Omega}$ (of size $Q T \times Q T$ ), where $\mathbf{I}_{\mathbf{Q}}$ is an identity matrix of size $Q$. Note also that the error vector $\boldsymbol{\varepsilon}_{\mathrm{t}}$ is distributed multivariate normal with a mean vector of zero and a temporal autoregressive covariance matrix $\Lambda$ (of size $T \times T$ ) given below: 


$$
\boldsymbol{\Lambda}=\left[\begin{array}{ccccc}
1 & \rho & \rho^{2} & \cdots & \rho^{T-1} \\
\rho & 1 & \rho & \cdots & \rho^{T-2} \\
\rho^{2} & \rho & 1 & \cdots & \rho^{T-3} \\
\vdots & \vdots & \vdots & \cdots & \vdots \\
\rho^{T-1} & \rho^{T-2} & \rho^{T-3} & \cdots & 1
\end{array}\right]
$$

Then, the error vector $\varepsilon$ is distributed multivariate normal with a mean vector of zero and a covariance matrix $\mathbf{\Lambda} \otimes \mathbf{I}_{\mathbf{Q}}$ (of size $Q T \times Q T$ ).

Using the vector and the matrix notations defined above, Equation (1) may be re-written compactly as:

$\mathbf{y}^{*}=\delta\left(\mathbf{I}_{\mathbf{T}} \otimes \mathbf{W}\right) \mathbf{y}^{*}+\mathbf{x b}+\widetilde{\mathbf{x}} \widetilde{\boldsymbol{\beta}}+\boldsymbol{\varepsilon}$,

where $\mathbf{I}_{\mathbf{T}}$ is an identity matrix of size $T$. After further matrix manipulation to write $\mathbf{y}^{*}$ in reduced form, we obtain:

$\mathbf{y}^{*}=\mathbf{S x b}+\mathbf{S} \widetilde{\mathbf{x}} \widetilde{\boldsymbol{\beta}}+\mathbf{S} \boldsymbol{\varepsilon}, \quad \mathbf{S}=\left[\mathbf{I}_{\mathbf{Q T}}-\delta\left(\mathbf{I}_{\mathbf{T}} \otimes \mathbf{W}\right)\right]^{-1}=\mathbf{I}_{\mathbf{T}} \otimes\left[\left(\mathbf{I}_{\mathbf{Q}}-\delta \mathbf{W}\right)^{-1}\right]$

The expected value and the variance of $\mathbf{y}^{*}$ are then as follows:

$E\left(\mathbf{y}^{*}\right)=\mathbf{S x b}=\mathbf{B}$, and

$\operatorname{Var}\left(\mathbf{y}^{*}\right)=\mathbf{S} \widetilde{\mathbf{x}}\left(\mathbf{I}_{\mathbf{Q}} \otimes \mathbf{\Omega}\right) \widetilde{\mathbf{x}}^{\prime} \mathbf{S}^{\prime}+\mathbf{S}\left(\mathbf{\Lambda} \otimes \mathbf{I}_{\mathbf{Q}}\right) \mathbf{S}^{\prime}=\mathbf{\Sigma}$

An important point from the reduced form in Equation (3) is that our contemporaneous spatial lag formulation specifies a spatial externality effect due to the time-invariant random coefficients too (see the $\mathbf{S} \widetilde{\mathbf{x}} \widetilde{\boldsymbol{\beta}}$ component on the right side of Equation (3)). That is, spatial dependence is implicitly generated in the observation-unit specific (time-invariant) coefficients. For instance, the preference and responsiveness to signals relevant to decision-making (such as how land owners respond to market place proximity or to proximity to lakes and other recreation centers) may themselves be correlated based on proximity of landowners' parcels. This is in 
addition to the usual "spillover" effects (or spatial externality effects) originating from the exogenous variables $(\mathbf{x})$ and the error terms $(\boldsymbol{\varepsilon}){ }^{2}$

\subsection{Estimation Approach}

The parameter vector to be estimated is $\boldsymbol{\theta}=\left(\mathbf{b}^{\prime}, \psi_{1}, \psi_{2}, \psi_{3}, \cdots, \psi_{L-1}, \boldsymbol{\omega}, \delta, \rho\right)^{\prime}$, where $\boldsymbol{\omega}$ is a column vector obtained by vertically stacking the lower triangle elements of the matrix $\mathbf{L}$ (recall that $\boldsymbol{\Omega}=\mathbf{L} \mathbf{L}^{\prime}$ ). Let the actual observed land development intensity level of spatial unit $q$ at time period $t$ be $m_{q t}\left(m_{q t} \in\{1,2, \ldots, L\}\right)$. Then, the likelihood function for the model is:

$$
L(\boldsymbol{\theta})=P(\mathbf{y}=\mathbf{m})=\int_{D_{y^{*}}} \phi_{Q T}\left(\mathbf{y}^{*} \mid \mathbf{b}, \mathbf{\Sigma}\right) d \mathbf{y}^{*},
$$

where $\quad D_{y^{*}}=\left\{\boldsymbol{y}^{*}: \psi_{\left(q, m_{q t}-1, t\right)}<y_{q t}^{*}<\psi_{q, m_{q t}, t}, \forall q=1,2, \ldots, Q, t=1,2, \ldots, T\right\}$ and $\phi_{Q T}($.$) is the$ multivariate normal density function of dimension $Q T$. $\mathbf{m}$ is a $Q T \times 1$-vector of observed ordinal outcomes as follows: $\mathbf{m}=\left(m_{11}, m_{21}, m_{31}, \ldots, m_{Q 1}, m_{12}, m_{22}, m_{32}, \ldots, m_{Q 2}, \ldots, m_{1 T}, m_{2 T}, m_{3 T}, \ldots, m_{Q T}\right)^{\prime}$. The integration domain $D_{y^{*}}$ is simply the multivariate region of the elements of the $\mathbf{y}^{*}$ vector determined by the observed vector of ordinal outcomes.

The dimensionality of the rectangular integral in the likelihood function is $Q T$. As discussed earlier, the use of numerical simulation techniques based on a maximum simulated likelihood (MSL) approach or a Bayesian inference approach, even if feasible, can lead to convergence problems during estimation (Bhat et al., 2010b; Müller and Czado, 2005). The alternative is to use the composite marginal likelihood (CML) approach, as discussed in Section 1.1. In the current study we use the pairwise composite marginal likelihood method based on the product of the likelihood contributions from pairs of observation units across time periods. To write this function, define two threshold vectors of size $Q T \times 1$ as follows:

$$
\begin{aligned}
& \boldsymbol{\tau}=\left(\psi_{1, m_{11}-1,1}, \psi_{2, m_{21}-1,1}, \ldots, \psi_{Q, m_{Q 1}-1,1}, \psi_{1, m_{12}-1,2}, \psi_{2, m_{22}-1,2}, \ldots, \psi_{Q, m_{Q 2}-1,2}, \ldots \psi_{1, m_{1 T}-1, T}, \psi_{2, m_{2 T}-1, T}, \ldots, \psi_{Q, m_{Q T}-1, T}\right)^{\prime} \\
& \vartheta=\left(\psi_{1, m_{11}, 1}, \psi_{2, m_{21}, 1}, \ldots, \psi_{Q, m_{Q 1}, 1}, \psi_{1, m_{12}, 2}, \psi_{2, m_{22}, 2}, \ldots, \psi_{Q, m_{Q 2}, 2}, \ldots \psi_{1, m_{1 T}, T}, \psi_{2, m_{2 T}, T}, \ldots, \psi_{Q, m_{Q T}, T}\right)^{\prime} .
\end{aligned}
$$

\footnotetext{
${ }^{2}$ The spatially structured effects probit model used in earlier studies that accommodates random effects at an aggregate regional level (see LeSage and Pace, 2009 and the references therein) is a restrictive spatial dependency specification compared to the one adopted here. In particular, if the only random coefficient was on the constant term, and this randomness was at an aggregate region level rather than a disaggregate parcel level, and if there are no additional spatial externality effects due to exogenous variables and the error term $\varepsilon$, then the spatial dependency in the reduced form of Equation (4) is similar to that in the spatially structured effects probit model.
} 
Let $g$ be an index that can takes the values from 1 to $Q T$. Then,

$$
\begin{aligned}
L_{C M L}(\boldsymbol{\theta}) & =\left(\prod_{g=1}^{Q T-1} \prod_{g^{\prime}=g+1}^{Q T} P\left([\mathbf{y}]_{g}=[\mathbf{m}]_{g},[\mathbf{y}]_{g^{\prime}}=[\mathbf{m}]_{g^{\prime}}\right)\right) \\
& =\left(\prod_{g=1}^{Q T-1} \prod_{g^{\prime}=g+1}^{Q T}\left[\begin{array}{c}
\Phi_{2}\left(\varphi_{\mathrm{g}}, \varphi_{\mathrm{g}^{\prime}}, v_{g g^{\prime}}\right)-\Phi_{2}\left(\varphi_{\mathrm{g}}, \mu_{\mathrm{g}^{\prime}}, v_{g g^{\prime}}\right) \\
-\Phi_{2}\left(\mu_{\mathrm{g}}, \varphi_{\mathrm{g}^{\prime}}, v_{g g^{\prime}}\right)+\Phi_{2}\left(\mu_{\mathrm{g}}, \mu_{\mathrm{g}^{\prime}}, v_{g g^{\prime}}\right)
\end{array}\right]\right),
\end{aligned}
$$

where $\varphi_{\mathbf{g}}=\frac{[\vartheta]_{g}-[\mathbf{B}]_{g}}{\sqrt{[\boldsymbol{\Sigma}]_{g g}}}, \mu_{g}=\frac{[\boldsymbol{\tau}]_{g}-[\mathbf{B}]_{g}}{\sqrt{[\boldsymbol{\Sigma}]_{g g}}}, v_{g g^{\prime}}=\frac{[\mathbf{\Sigma}]_{g g^{\prime}}}{\sqrt{[\boldsymbol{\Sigma}]_{g g}} \sqrt{[\boldsymbol{\Sigma}]_{g^{\prime} g^{\prime}}}}$.

In the above expression, $[\vartheta]_{g}$ represents the $g^{\text {th }}$ element of the column vector $\vartheta$, and similarly for other vectors. $[\Sigma]_{g g}$ represents the $g g^{\text {th }}$ element of the matrix $\boldsymbol{\Sigma}$. The CML estimator is obtained by maximizing the logarithm of the function in Equation (6). The asymptotic covariance matrix $\mathbf{V}_{C M L}(\hat{\boldsymbol{\theta}})$ may be computed from the Godambe sandwich information matrix as discussed in detail in Bhat (2011).

The pairwise marginal likelihood function of Equation (6) comprises $Q T(Q T-1) / 2$ pairs of bivariate probability computations, which can itself become quite time consuming. Fortunately, in a spatial-temporal case where spatial dependency drops quickly with interobservation distance, the pairs formed from the closest spatial observation units provide much more information than pairs from spatial units that are far away. In fact, as demonstrated by Varin and Vidoni (2009), Bhat et al. (2010b), and Varin and Czado (2010) in different empirical contexts, retaining all pairs not only increases computational costs, but may also reduce estimator efficiency. We examine this issue by creating different distance bands and, for each specified distance band, we consider only those pairings in the CML function that are within the spatial distance band. Then, we develop the asymptotic variance matrix $\mathbf{V}_{C M L}(\hat{\boldsymbol{\theta}})$ for each distance band and select the threshold distance value that minimizes the total variance across all parameters as given by $\operatorname{tr}\left[\mathbf{V}_{C M L}(\hat{\boldsymbol{\theta}})\right]$ (i.e., the trace of the matrix $\left.\left[\mathbf{V}_{C M L}(\hat{\boldsymbol{\theta}})\right]\right)$.

A final issue regarding estimation. The positive definiteness of $\boldsymbol{\Sigma}$ is ensured as long as $0<\delta<1,0<\rho<1$ and the matrix $\boldsymbol{\Omega}$ is positive-definite. To ensure the constraints on the autoregressive terms $\delta$ and $\rho$, we parameterize these terms as $\delta=1 /[1+\exp (\tilde{\delta})]$ and $\rho=1 /[1+\exp (\widetilde{\rho})]$, respectively. Once estimated, the $\widetilde{\delta}$ and $\widetilde{\rho}$ estimates can be translated back 
to estimates of $\delta$ and $\rho$. The matrix $\mathbf{\Omega}$ can be guaranteed to be positive definite by writing the logarithm of the pairwise-likelihood in terms of the Cholesky-decomposed elements of $\mathbf{\Omega}$ and maximizing with respect to these elements of the Cholesky factor. That is, we write $\boldsymbol{\Omega}$ as $\mathbf{L} \mathbf{L}^{\prime}$ (where $\mathbf{L}$ is the lower triangular Cholesky factor of $\mathbf{\Omega}$ ), and estimate the elements of the matrix L.

\section{SIMULATION STUDY}

In this section, we undertake a simulation experiment with two objectives in mind. The first objective is to examine the ability of the proposed CML inference approach to recover the parameters of the spatial panel ordered-response model in this paper. The second is to examine the effects of ignoring spatial dependence and spatial heterogeneity (when both are actually present).

\subsection{Experimental Design}

To set up the experiment, we generate 400 observations (i.e., $Q T=400$ ) using prespecified values for the $\boldsymbol{\theta}$ vector. We assume that the generated observations correspond to 100 parcels (i.e., $Q=100$ ) and 4 time periods (i.e., $T=4$ ). We further assume that there are three ordered categories of the observed land use development intensity level and the corresponding threshold values are set to $-1\left(\psi_{1}\right)$ and $1\left(\psi_{2}\right)$. We also consider three independent variables $(\mathbf{x})$ in the analysis, all of which are drawn from standard univariate normal distributions. We consider the coefficient on the first variable to be fixed, but allow randomness in the next two elements of the coefficient vector. Specifically, the covariance matrix of $\boldsymbol{\beta}_{\mathrm{q}}$ is specified to be as follows:

$$
\boldsymbol{\Omega}=\left[\begin{array}{ccc}
0 & 0 & 0 \\
0 & \sigma_{22}^{2} & 0 \\
0 & 0 & \sigma_{33}^{2}
\end{array}\right]=\left[\begin{array}{lll}
0 & 0 & 0 \\
0 & 1 & 0 \\
0 & 0 & 1
\end{array}\right]
$$

The mean vector for $\boldsymbol{\beta}_{\mathrm{q}}$ is set to $\mathbf{b}=(0.5,0.8,1)$. Next, we generate the weight matrix $(\mathbf{W})$ by borrowing the spatial locations of 100 parcels in Austin, Texas, based on the 2008 land use survey data that is used in the empirical analysis of this paper (see Section 4). While several different functional forms may be used to generate the weights from the spatial configuration of the 100 parcels, we use a continuous inverse of distance specification in this simulation analysis. 
We also consider all the $Q T(Q T-1) / 2$ pairs of bivariate probability computations in the composite marginal likelihood function for the simulation. To examine the potential impact of different levels of spatial and temporal dependence on the ability of the CML approach to recover model parameters, we consider two values of the spatial autoregressive coefficient $\delta$ corresponding to low dependence $(\delta=0.25)$ and high dependence $(\delta=0.75)$, as well as two values of the temporal autoregressive coefficient $\rho$ corresponding to low dependence $(\rho=0.25)$ and high dependence $(\rho=0.75)$. Thus, in total, there are four possible combinations of the spatial and temporal autoregressive coefficients considered in the simulations.

The set-up above is used to develop the $\mathbf{B}$ matrix and the $\boldsymbol{\Sigma}$ matrix (see Equation (4)) for each of the four combinations just discussed. A $(Q T \times 1)$ vector of the latent variable $\mathbf{y}^{*}$ (in Equation (3)) is drawn from the multivariate normal distribution with mean $\mathbf{B}$ and covariance structure $\boldsymbol{\Sigma}$. The generated latent variables are then translated into the "observed" vector $\mathbf{y}$ using the specified threshold values. For each of the four combinations, the data generation process is undertaken 20 times with different realizations of the latent variable $\mathbf{y}^{*}$ from the values of $\mathbf{B}$ and $\Sigma$.

The CML estimation procedure is applied to each data set to estimate data-specific values of the vector $\boldsymbol{\theta}=\left(\mathbf{b}^{\prime}, \psi_{1}, \psi_{2}, \sigma_{22}, \sigma_{33}, \delta, \rho\right)^{\prime}$. The Godambe information-based covariance matrix and the corresponding standard errors are also computed. Finally, for each of the four combinations of the spatial and temporal dependency coefficients, the mean estimate for each model parameter across the twenty data sets is obtained and a parameter-specific mean absolute percentage bias or APB value (relative to the "true" value of the parameter) is computed. Similarly, the mean standard error for each model parameter is computed across the twenty data sets and is labeled as the asymptotic standard error (ASE) for the parameter.

The main purpose of the methodology proposed here is to accommodate spatial dynamics and spatial heterogeneity in the context of panel data. Therefore, to examine the potential problems that could arise from ignoring spatial dynamics and spatial heterogeneity, we estimate two additional models on the twenty data sets generated for each combination of spatial and temporal dependence levels. The first model ignores the spatial autocorrelation coefficient $\delta$ (that is, assumes $\delta=0$ ), while the second model assumes away any spatial heterogeneity (that is, 
assumes that all elements of the covariance matrix $\boldsymbol{\Omega}$ are identically zero). ${ }^{3}$ For ease in presentation, we will refer to the first model as the ordered-response model with spatial heterogeneity (or the ORH model), and the second model as the ordered-response model with spatial dependence (or the ORS model). We compare these two restrictive formulations with the general ordered-response model with spatial dependence and heterogeneity (or the ORSH model), based on the mean APB measure across all parameters and the adjusted composite loglikelihood ratio test (ADCLRT) value (see Pace et al., 2011 and Bhat, 2011 for more details on the ADCLRT statistic, which is the equivalent of the log-likelihood ratio test statistic when a composite marginal likelihood inference approach is used; this statistic has an approximate chisquared asymptotic distribution). The ADCLRT statistic needs to be computed for each data set separately, and compared with the chi-squared table value with the appropriate degrees of freedom. Here we identify the number of times (out of the 20 model runs corresponding to the 20 data sets) that the ADCLRT value rejects the ORH and ORS models in favor of the ORSH model.

\subsection{Simulation Results}

Tables $1 \mathrm{a}$ and $1 \mathrm{~b}$ provide the results for the ability of the CML approach to recover the parameters of the spatial panel ordered-response model, while Table 2 provides the results showing the implications of ignoring spatial dynamics and spatial heterogeneity when present. We discuss these results in the subsequent two sections, each section focusing on a specific objective of the simulation exercise.

\subsubsection{Ability of CML to Recover Model Parameters}

In the low spatial autoregressive coefficient $(\delta)$ case in Table 1a, the absolute percentage bias (APB) ranges from $0.03 \%$ to $6.22 \%$ for the low temporal autoregressive coefficient $(\rho)$ case (overall mean value of $2.28 \%$ - see last row of table under the sub-column titled "absolute percentage bias"), and from $0.09 \%$ to $7.67 \%$ for the high temporal autoregressive coefficient case (overall mean value of $3.06 \%$ ). In the high spatial autoregressive coefficient case (see Table

\footnotetext{
${ }^{3}$ Of course, as indicated earlier, setting all elements of $\boldsymbol{\Omega}$ to zero also implies the absence of time-stationary temporal dependence across observations for the same parcel, as well as leads to a reduction in spatial dependence (see Section 2.2).
} 
1b), the APB ranges from $2.50 \%$ to $7.62 \%$ for the low $\rho$ case (mean of $5.05 \%$ ), and from $0.55 \%$ to $13.74 \%$ for the high $\rho$ case (mean of $6.88 \%$ ). Overall, these are very good measures for the ability to recover parameter estimates, and indicate that the CML is able to recover parameters well. Of course, the results indicate that the recovery of parameters is particularly good for the mean of the coefficients on the exogenous variables (the APB values for the $\mathbf{b}$ vector elements are, in general, less than 5\%; see the first numeric row panel of Tables 1a and 1b). On the other hand, the standard deviations of the coefficients on the exogenous variables (i.e., the $\sigma_{22}$ and $\sigma_{33}$ parameters that correspond to the square root of the elements of the $\boldsymbol{\Omega}$ matrix) are better recovered for the case of low spatial dependence than for the case of high spatial dependence (see the higher APBs corresponding to these parameters in the third numeric row panel of Table $1 \mathrm{~b}$ compared to Table 1a). This is not surprising, since these covariance parameters enter the likelihood function in a more complex non-linear fashion in general than the mean parameters of the coefficients. This is particularly so in the presence of high spatial dependence, since the $\mathbf{S}$ matrix gets applied in a non-linear fashion to the $\boldsymbol{\Omega}$ matrix during estimation (see Equation (4)). But when the spatial dependence is low, the non-linear effect is not as high as in the case of the high spatial dependence case, leading to the better recovery ability of the standard deviation parameters. The results also indicate that the ability to recover the threshold parameters (i.e., $\psi_{1}$ and $\left.\psi_{2}\right)$ is, in general, better and more stable in the case of low temporal dependence than in the case of high temporal dependence (see the lower APBs corresponding to these threshold parameters in Tables 1a and 1b). This is an issue that needs further exploration in future studies.

Finally, there are also patterns in the ability to recover the spatial and temporal autoregressive parameters. For the low spatial autoregressive parameter $(\delta=0.25)$, the APB values are $0.58 \%$ and $3.45 \%$ for the low and high temporal autoregressive coefficient cases, respectively. For the high spatial autoregressive parameter $(\delta=0.75)$, the corresponding APB values are $7.62 \%$ and $10.14 \%$, respectively. The implication is that the spatial dependency parameter may be relatively easy to recover when the magnitudes of the spatial and temporal dependency autoregressive coefficients are both small. However, for the temporal dependency parameter $\rho$, the results indicate very good recovery and stability for all different combinations of the $\delta$ and $\rho$ parameters. This is because the parameter $\rho$ is directly associated with the magnitude of correlation across observations on the same spatial unit, and changes in this 
parameter will have immediate and substantial impacts on the log-likelihood function (regardless of the magnitude of the spatial dependency effect or the magnitude of $\rho$ itself).

The asymptotic standard error (ASE) values of the parameters indicate that the CML estimator appears to be quite efficient. In particular, the ASE values of all the parameters, except $\delta$ and $\rho$, range from $1-4 \%$ of the mean estimates. For $\delta$ and $\rho$, the ASE values range from $0.5-8.2 \%$ and $0.7-8.9 \%$ of the mean estimates, respectively.

\subsubsection{Effects of Ignoring Spatial Effects}

This section focuses on the implications of ignoring each of spatial dynamics and spatial heterogeneity when both are present. To examine the effect of ignoring spatial dynamics when present, the results of the ORH model may be compared with those from the ORSH model. On the other hand, to assess the impact of ignoring spatial heterogeneity when present, the results of the ORS model may be compared with those from the ORSH model. Table 2 provides the results. As may be observed, two sets of mean APB values (across model parameters) are computed for the ORSH model, one for comparison with the ORH model and another for comparison with the ORS model. For comparison with the ORH model, the mean APB values for the ORSH model are computed without considering the APB values for the $\delta$ parameter, because the $\delta$ parameter is implicitly fixed at zero in the ORH model. For comparison with the ORS model, the mean APB values for the ORSH model are computed without considering the APB values for the $\sigma_{22}$ and $\sigma_{33}$ parameters (that correspond to the square root of the elements of the $\boldsymbol{\Omega}$ matrix characterizing spatial heterogeneity). Note again that the $\sigma_{22}$ and $\sigma_{33}$ parameters are implicitly fixed to zero in the ORS model.

The results indicate that the mean APB values are higher for the ORH and ORS models than for the ORSH model. Not surprisingly, the ORH model performs better in the two low spatial dependence cases than in the two high spatial dependence cases, since ignoring spatial dependence when such dependence is low should be of less consequence than ignoring such dependence when high. However, even in the two low spatial dependence cases, the ORH model may be rejected compared to the "correct" ORSH specification based on the adjusted composite likelihood ratio test (ADCLRT) statistic (note that the ORSH specification rejects the simpler ORH and ORS specifications for each of the twenty data sets generated). The results also 
indicate that the ORS model (which ignores spatial heterogeneity) performs very poorly across the board. In this regard, we should also point out that the ORSH and ORH models always converged, while the ORS model experienced occasional convergence-related problems in the high spatial dependence case. In particular, because of convergence problems, the results in Table 2 for the ORS model are based on estimations on fifteen data sets for the $(\delta=0.75, \rho=$ $0.25)$ case and on eighteen data sets for the $(\delta=0.75, \rho=0.75)$ case. Also, the ORS model is clearly outperformed by the ORSH model.

Overall, the simulation results show that, irrespective of the magnitude of spatial and temporal dependences, the CML estimator recovers the parameters of the spatial panel orderedresponse model very well. The CML estimator also seems to be quite efficient based on the low asymptotic standard error estimates of the parameters compared to the mean estimates of the parameters. In addition, the results clearly highlight the bias in estimates if spatial dependence and/or spatial heterogeneity are ignored when both are actually present. An interesting suggestion from our simulation study is that ignoring spatial heterogeneity is of much more serious consequence than ignoring spatial lag dynamics. Further theoretical and empirical exploration of this finding is left for future work.

\section{DATA}

\subsection{Data Sources}

The primary data used in the empirical exercise of this paper is drawn from the land use data sets collected by the City of Austin Watershed Protection and Development Review Department for the years 2000, 2003, 2006, and 2008 (City of Austin, 2011). ${ }^{4}$ For each analysis year, the land use information considered in the empirical analysis represents the ground land use condition at that time. ${ }^{5}$ The City of Austin uses a 3-digit land use code that classifies the collected information into different land use types such as single-family, multi-family, mobile homes, apartment/condo, group quarters, office, industrial, and open space/vacant land (see City of Austin, 2011 for a complete list of land use classifications). This land use information is

\footnotetext{
${ }^{4} 2008$ is the latest year for which land use information for the City of Austin is available.

${ }^{5}$ Specifically, the data sets describe ground conditions in October 2000, June 2003, June 2006, and October 2008, which are about equally spaced in time (the time period between successive data collection efforts spans between 2 years 4 months and 3 years).
} 
maintained at a parcel-level spatial resolution and made available to the public in Geographic Information System (GIS) format (shape file format).

In addition to the land use information, several other GIS data sets/layers were obtained from the City of Austin (2011) and the Capital Area Council of Governments (CACOG, 2011). These secondary GIS data sets included a transportation network layer, a school location layer, a park location layer, a water body location layer, an aircraft landing facility location layer, a contour layer with information on average elevation at different points in the study area, and a layer on city boundaries for Austin and other neighboring cities.

\subsection{Sample Formation and Description}

The land use data (and the data from the secondary sources) were processed in several steps to obtain the sample for the current analysis. First, the land use GIS layers (created by the City of Austin) for the years 2000, 2003, 2006, and 2008 were spatially merged. Second, a 1.75 square miles (4.53 square kilometers) area near the western boundary of the City of Austin was selected for this study. This area was selected because the land use pattern here has undergone substantial changes between 2000 and 2008. Third, information on the land use of each parcel in each year was translated into four mutually exclusive ordinal land development intensity categories for this study: (1) undeveloped land (includes open space, rural area, agricultural land, and vacant parcels), (2) land developed with low level of intensity (includes residential parcels with singlefamily detached and two-family attached homes, (3) land developed with medium level of intensity, including all other types of residential parcels such as apartment, condo, three/fourplex, group quarters, and retirement homes), and (4) land developed with high level of intensity, including parcels developed for office, commercial, and industrial use). Note, however, that the development intensity classification used in the application demonstration exercise here is simply one of many that may be used by the analyst. Specifically, the intensity classification may be customized to the planning purpose at hand. Fourth, variables derived from the secondary data sources were appended to the parcel-level data. The final sample for analysis includes land use information for 783 parcels.

Table 3 presents the number (and the percentage) of parcels by land use development intensity (LUDI) and year of observation. The table clearly indicates the rapid pace of development between 2003 and 2006, which is consistent with the general ground reality in the 
Austin area (see http://www.austintexas.gov/page/growth-watch-data-years). While 36-37\% of the land parcels were undeveloped in 2000 and 2003, this percentage drops to $10-13 \%$ by 2006 and beyond. During the analysis time period, the shares of medium-intensely and most-intensely developed parcels remained somewhat constant, indicating that the land owners found converting undeveloped parcels to less-intensely developed parcels to be the most profit maximizing investment. In terms of the independent variables, these were time-invariant since the GIS layers corresponding to parcels and those of lakes, public airfields, schools, and elevations did not change over time for the region of analysis under consideration in the current paper (however, variations in these independent variables pose no problems for our estimation procedure).

\section{EMPIRICAL ANALYSIS}

\subsection{Model Selection and Variable Specification}

Several weight matrix specifications were considered in our empirical analysis to characterize the nature of the dynamics of the spatial lag dependence. These included (1) a contiguity specification that generates spatial dependence based on whether or not two parcels are contiguous, (2) another contiguity specification but based on shared boundary length, (3) the inverse of a continuous distance specification where the distance is measured as the Euclidean distance (crow fly distance) from the centroids of each parcel, (4) the inverse of the square of the continuous distance specification, and (5) the inverse of the exponential of the continuous distance specification. For the last three continuous distance-based specifications, we also explored alternative distance bands to select the pairs of observations for inclusion in the composite marginal likelihood (CML) estimation. As indicated earlier, this distance band determination may be based on minimizing the trace of the variance matrix of parameters given by $\operatorname{tr}\left[\mathbf{V}_{C M L}(\hat{\boldsymbol{\theta}})\right]$. Our results did not show substantial variations in the trace value for different distance bands (regardless of the specific continuous functional form used to represent the distance separation and the variable specification used), though the best estimator efficiency was obtained at about 0.25 miles for all the three continuous distance specifications formulations and all variable specifications we attempted. Further, the results indicated that for all variable specifications, the best spatial weight matrix specification was consistently the inverse of the continuous distance specification with the 0.25 mile distance band. This determination was based on the composite likelihood information criterion (CLIC) statistic, which may be used to 
compare the data fit of non-nested formulations (see Varin and Vidoni, 2005). This CLIC statistic takes the form shown below:

$$
\mathrm{CLIC}=\log L_{C M L}(\hat{\boldsymbol{\theta}})-\operatorname{tr}\left[\hat{\mathbf{J}}(\hat{\boldsymbol{\theta}}) \hat{\mathbf{H}}(\hat{\boldsymbol{\theta}})^{-1}\right]
$$

where $\hat{\boldsymbol{\theta}}$ is the estimated model parameter vector, and $\hat{\mathbf{J}}(\hat{\boldsymbol{\theta}})$ and $\hat{\mathbf{H}}(\hat{\boldsymbol{\theta}})$ are the "vegetable" and "bread" matrices used in the estimation of the asymptotic variance matrix $\mathbf{V}_{C M L}(\hat{\boldsymbol{\theta}})$ (see Bhat, 2011 for details of how these matrices may be estimated in a spatial context). In the current context, the weight specification that provides the highest value of the CLIC statistic is preferred over the other competing weight specifications. Of all the weight matrix specifications that were considered here, the best three specifications and the corresponding CLIC statistics are presented in Table 4. These statistics correspond to the best variable specification that emerged from our empirical analysis (see the next paragraph for more on this) and for the optimal distance band of 0.25 miles for the continuous distance weight specifications. The results in the table clearly show the superiority of the inverse of the continuous distance specification over other weight matrix specifications. Thus, all subsequent results in this paper correspond to the inverse distance weight specification with a 0.25 mile distance band.

Concurrent with the weight matrix specification, we also explored several different variable specifications and functional forms of the variables. The final specification included the following three sets of variables: (1) proximity (in the form of distance) to natural amenities (such as parks and lakes), schools, and the central business district (CBD) area of Austin ${ }^{6},(2)$ ease of access to the transportation system (distance to Interstate IH-35 and distance to a public airfield), and (3) year-specific dummy variables (for the years 2006 and 2008) and geographic location/contour variables (whether or not the parcel is located within the Austin City limit and the average elevation of a parcel above the sea level). For the first two sets of variables, several linear and non-linear functional forms were considered (such as the logarithm of distance, the square of distance, and spline variables that allow piece-wise linear effects of distance on the utilities). In addition, we also considered dummy variables for different ranges of distance for these variables (for instance, parcel is within 2 miles of a park and parcel is within 5 miles of a

\footnotetext{
${ }^{6}$ Parks as used here refers to such natural outdoor recreations areas as parks, greenbelts, and nature preserves. Similarly, a lake as used here refers to either Lake Travis, Lake Austin, Lady Bird Lake, Walter E. Long Lake, or Colorado River.
} 
park). Further, various interactions of the many variables were also considered whenever adequate observations were available to test such interaction effects. The final specification was based on intuitive, data fit, and statistical significance considerations. Interestingly, all the distance variables were best reflected as dummy variables in this final specification, though the threshold value for translation of the distance variables to the dummy variables varied across the variables. The final specification includes some variables that are not statistically significant at the usual 5\% level of significance. These are retained because the effects of these variables are intuitive and may provide guidance in future research efforts. The results of the final specification are discussed in the next section.

\subsection{Model Estimation Results}

Table 5 presents the model estimation results. The column titled "Parameter - Mean Estimate" provides the mean estimate of each parameter and the corresponding t-statistic of the mean estimate. Each of these estimates provides the mean effect of the corresponding row variable on the land use development returns (LUDR) perception of land owners. Since all the variables in the final specification appear as dummy variables, the relative magnitudes of the mean effects provide an estimate of the importance of the variable in affecting the LUDR perception of land owners. Note also that we attempted a (normally distributed) random coefficients specification for the variables through a general specification of the $\boldsymbol{\Omega}$ matrix. However, only the variance parameters corresponding to the constant, "distance to a lake", and "distance to an airfield" variables turned out to be statistically significant. Further, we could not reject the null hypothesis that the off-diagonal (covariance) elements of the $\boldsymbol{\Omega}$ matrix corresponding to these random coefficients were all zero. The column titled "Parameter - Standard Deviation Estimate" provides the standard deviation estimates of the random coefficients and their corresponding t-statistics.

The first variable in Table 5 corresponds to the constant, whose mean estimate is fixed at zero for identification. However, the statistically significant estimate of the standard deviation on the constant indicates that there is unobserved heterogeneity in the LUDR perception across land owners, attributable to such unobserved factors as individual experiences, risk-taking behavior, and vegetation conservation values. In the following sections, we discuss the effects of the nonconstant variables on the latent LUDR perception by variable category. 


\subsubsection{Proximity to Natural Amenities, School, and the CBD}

The effects of this set of variables suggests that parcels located within close proximity of a park (distance $\leq 2$ miles) and/or a lake (distance to a lake $\leq 5$ miles distance) are perceived by land owners as providing high returns to development relative to parcels located farther away from such natural amenities. These effects are to be expected, since areas with good access to natural recreation are prime profitable locations for residential land use (see Geoghegan 2002). Interestingly, however, the results show substantial variation in the LUDR perceptions of land owners of parcels within 5 miles of a lake, with 32\% of landowners having a negative LUDR perception and $68 \%$ having a positive LUDR perception. This may suggest variations in nature conservation values across land-owners, so that some land owners of parcels close to lakes may place a high premium on keeping their land undeveloped and "pristine".

Proximity to a school also affects land development intensity level. As expected, owners of parcels close to a school (school $\leq 2$ miles) are likely to perceive their parcels as having high development value (see $\mathrm{Li}$ and $\mathrm{Liu}, 2007$ ). The final variable in this category indicates a lower LUDR perception for parcels located in close proximity $(\leq 9$ miles $)$ of the Austin CBD relative to those located farther away ( $>9$ miles). This is interesting, and suggests the tension between the urban amenities (access to retail places and public services such as hospitals) on the one hand that may increase the demand for development in already densely developed areas, and the urban "disamenities" (such as traffic congestion effects and air quality problems) on the other hand that may decrease demand for development in already dense neighborhoods (see Irwin and Bockstael, 2002, and Carrión-Flores and Irwin, 2004). According to our results, the "disamenities" effect exceeds the "amenities" effect offered by parcels located in close proximity to the Austin CBD area, leading to an overall negative LUDR perception for these parcels.

\subsubsection{Ease of Access to the Transportation System}

Several earlier studies (for instance, see Carrión-Flores and Irwin, 2004 and Chakir and Parent, 2009) have found that proximity and access to major roadways generally has a positive impact on development intensity (even if certain kinds of developments such as industrial facilities are precluded by zoning regulations to be located very close to major roadways). The result on the "distance to IH-35" variable in Table 5 is consistent with these earlier studies, and indicates that 
parcels in the analysis area within 9 miles of IH-35 are less likely to be in an undeveloped state than parcels farther away from IH-35.

The second variable in the "access to transportation system" category shows that land owners of parcels that are proximal to a public airfield (distance to an airfield $\leq 1$ mile) are, on average, likely to have a negative perception of the profitability of development of their land; that is, these land owners are more likely to keep their land undeveloped than invest money in development. This is perhaps because of noise pollution and air space invasiveness effects of aircrafts landing or taking off from airfields. However, it is important to note that there is heterogeneity in the LUDR perception of land owners of parcels close to airfields, with $25 \%$ of land-owners perceiving a positive LUDR (see the standard deviation estimate of the "distance to airfield $\leq 1$ mile" variable in Table 5). Such LUDR heterogeneity is not surprising, since some parcels close to airfields may not be that impacted by aircraft noise and space invasiveness because of the alignment of runways vis-à-vis the parcel location. For these parcels, the close proximity to air transport may be more of a "pull" effect than a "push" effect.

\subsubsection{Year-Specific Dummy Variables and Other Variables}

The dummy variables for 2006 and 2008 essentially reflect the higher propensity of parcels to be developed in some form or the other relative to 2000 and 2003. This trend of a higher development intensity pattern after 2005 (relative to before 2005) is consistent with the actual trend observed in land development intensity in the Austin area (see, for example, http://austin.housealmanac.com). The final two variables suggest that land owners of parcels located within Austin city limits and located at a lower elevation (less than or equal to $1000 \mathrm{ft}$ above sea level) have a lower LUDR perception than land owners of parcels located outside Austin city limits and at a higher elevation (more than $1000 \mathrm{ft}$ above sea level), respectively.

\subsubsection{Autoregressive Parameters and Thresholds}

The results indicate the presence of spatial dependence in land use development decisions. Specifically, the estimated spatial autoregressive coefficient $(\delta)$ is 0.905 and highly statistically significant, strongly supporting the hypothesis of the presence of spatial spillover effects in the LUDR perceptions of land owners of proximally located spatial units. That is, there is strong evidence of didactic interactions between land owners of proximally located parcels. 
The temporal autoregressive coefficient $(\rho)$ is also moderately statistically significant with a magnitude of 0.344 . This is evidence of the presence of land owner-specific unobserved effects that fade over time. Of course, this temporal fading effect is in addition to the timeinvariant unobserved effects that influence the LUDR perception of a land owner at all time points (as captured by the random coefficients on the constant, the "distance to a lake" variable, and the "distance to a public airfield" variable).

Finally, the thresholds values serve to translate the latent propensity into the observed ordered categories of the land use type.

\subsubsection{Overall Measures of Fit}

The results of the spatial panel ordered-response model with spatial dependence and heterogeneity (i.e., the ORSH model) estimated in the current paper show clear evidence of spatial heterogeneity, spatial lag dynamics due to didactic interactions between land owners, as well as time-variant temporal correlation in the LUDR perceptions of the same individual. Thus, the model estimated here is superior to a model that ignores these spatial and temporal effects. One can also assess the data fit degradation from ignoring spatial and temporal effects by estimating a simple ordered-response (OR) model that assumes away the presence of these spatial-temporal effects. An adjusted composite likelihood ratio test (ADCLRT) statistic can then be computed from the composite marginal log-likelihood (CML) value at convergence $(=-718,753)$ of the ORSH model estimated here and the CML value of the simple OR model $(=-734,701)$. This statistic has a chi-square asymptotic distribution with five degree of freedom, and soundly rejects the OR model at any reasonable level of significance (the ADCLRT value is 11,874 , which is higher than the chi-squared table value with five degrees of freedom at practically any level of significance). This again demonstrates very strong evidence of spatial dynamics and temporal dependence at play in land-use development intensity decisions.

\subsection{Elasticity Effects}

The parameter estimates presented in Table 5 do not directly provide the marginal effects of variables on the probability of the ordinal land use development intensity (LUDI) categories (as observed by Franzese and Hays, 2008, this is an issue seldom considered in the spatial choice literature, with many papers simply presenting the parameter results and stopping there). To 
obtain a sense of the marginal effects, we compute an "arc-elasticity effect" for each variable. Specifically, we develop the procedure to evaluate the effect of a change in an independent variable in a given year on the percentage change in the aggregate share of each ordinal land use development intensity (LUDI) category for a specified year, while accommodating the spatial and temporal dependency effects. The aggregate share (across parcels) for each LUDI category is obtained by aggregating the parcel-level probabilities for that category for the specified year (the probabilities themselves are computed as discussed in the next paragraph). Thus, the elasticity computed is a measure of the percentage change in the aggregate share of each LUDI category due to a change in an exogenous variable.

The procedure to compute the probability for an LUDI category for each parcel-year combination in the ORSH model (needed for the elasticity effects computations) is similar to that used to generate the data samples in our simulation experiment. Specifically, the estimated counterpart of $\boldsymbol{\theta}=\left(\mathbf{b}^{\prime}, \psi_{1}, \psi_{2}, \psi_{3}, \cdots, \psi_{L-1}, \boldsymbol{\omega}, \delta, \rho\right)^{\prime}$ (say $\hat{\boldsymbol{\theta}}$ ) is used to develop estimates of the $\mathbf{B}$ matrix (say $\hat{\mathbf{B}}$ ) and the $\boldsymbol{\Sigma}$ matrix (say $\hat{\boldsymbol{\Sigma}}$ ) in Equation (4). A $(Q T \times 1)$-vector realization of the latent variable $\mathbf{y}^{*}$ is next drawn from the multivariate normal distribution with mean $\hat{\mathbf{B}}$ and covariance structure $\hat{\boldsymbol{\Sigma}}$. The generated latent variables are then translated into the "observed" vector $\mathbf{y}$ using the estimated threshold values. This "observed" vector is immediately converted into a set of dummy variables for each parcel and each year, each dummy variable representing whether or not the parcel in each year is "observed" in each of the $L$ different LUDI categories. The procedure above of drawing realizations of $\mathbf{y}^{*}$ from the multivariate normal distribution with mean $\hat{\mathbf{B}}$ and covariance structure $\hat{\boldsymbol{\Sigma}}$ is repeated 1000 times, and the probability of a parcel being in each LUDI category for each year is computed as the average across the 1000 dummy variable value realizations for that LUDI category for the parcel-year combination.

In the current paper, we examine the elasticity effects of changes in variables in the year 2008 on the percentage changes in the shares of the LUDI categories in the year 2008. We also compute the standard errors of the elasticity effects by using 100 bootstrap draws from the multivariate sampling distribution of $\hat{\boldsymbol{\theta}} .^{7}$ All the exogenous variables in the current analysis are

\footnotetext{
${ }^{7}$ But note that one can also compute the arc elasticity effects over time using our procedure. For example, we can examine the effects of the location of a park in one year on the LUDI levels in subsequent years. However, to conserve on space, we focus in this paper on changes in variables in 2008 on the LUDI levels in 2008.
} 
introduced as dummy variables. To compute the pseudo-elasticity effects for each of these variables, the value of each variable is changed to one for the subsample of parcels for which the variable takes a value of zero, and to zero for the subsample of parcels for which the variable takes a value of one. The shifts in expected aggregate shares for each ordinal land use development intensity (LUDI) category in the two subsamples is then added after reversing the sign of the shift in the second subsample. Next, the effective percentage change in the expected share of each ordinal LUDI category is computed due to a change in the dummy variable from 0 to 1 .

The elasticity effects and their standard errors (in parenthesis) for the ORSH model and the simple ordered-response (OR) model are presented in Table 6, along with the p-value for the difference in elasticity estimates from the two models. The first entry under the "ORSH model" column in the table indicates that, on average, parcels located within a 2-mile radius of a park are $20.96 \%$ less likely to be undeveloped relative to parcels located more than 2 miles away from a park. The other entries under the "ORSH model" columns (and the "OR model" columns) may be similarly interpreted.

Several observations may be made from the results in Table 6. First, the numbers in the table indicate the relative importance of each exogenous variable in influencing the ordinal land use development intensity category. For instance, the ORSH model (and the OR model) results indicate that proximity to a lake is the most important determinant of intense land development, with parcels located closer to a lake ( $\leq 5$ miles) being about $150 \%$ (2.5 times) more likely to be intensely developed compared to parcels located far away ( $>5$ miles) from a lake (see the "ORSH model" and "OR model" sub-columns of the last column of Table 6 under the row "Distance to a lake $\leq 5$ miles"). On the other hand, parcels located near an airfield and within Austin city (at least in the context of the area used in the current demonstration exercise) are the least likely to be intensely developed. Similarly, parcels located far away from IH-35 (> 9 miles from IH-35) and parcels within Austin city limits are the most likely to be in an undeveloped state (see the first two numeric sub-columns in Table 6). Second, the elasticity effects of both the ORSH and the OR models are in the same direction. However, a visual comparison of the results indicates that the elasticity effects predicted by the ORSH model are higher than the OR model prediction (the only exception is the effect of "Parcel is located in Austin" variable on the mostintensely developed land use category). The higher magnitudes from the ORSH model reflect the 
spatial multiplier effect caused by spatial dependence. Specifically, a change in a variable relevant to one land owner (that has an impact on the LUDR perception of the land owner) also affects the LUDR perceptions of land owners of proximally located parcels, which then have a "circular" and reinforcing influence back on the LUDR perception of the land owner (this spatial multiplier effect is captured by the $\mathbf{S}$ matrix in Equation (3)). In contrast, the OR model ignores the presence of the "spillover" phenomenon and assumes away any spatial interaction effects among land owners. Finally, the entries in the p-value columns for each ordinal land use intensity category indicate that many of the differences in elasticity effects between the ORSH and OR models are statistically significant at the 0.1 level or lower, clearly underscoring the importance of accommodating spatial dynamics and spatial heterogeneity in the current empirical context.

\section{SUMMARY AND CONCLUSIONS}

This paper proposes and estimates a spatial panel ordered-response probit model with temporal autoregressive error terms to analyze changes in urban land development intensity level over time. Such a model structure maintains a close linkage between the land owner's decision (unobserved to the analyst) and the land development intensity level (observed by the analyst), and accommodates proximity-based spatial didactic interactions among the land owners that causes "spillover" effects. In addition, temporal dependency (due to unobserved factors) is generated across the LUDR perceptions of the same land owner over time - the effects of some of these factors may fade away over time, while the effects of other factors may remain timeinvariant. The model structure also incorporates (unobserved) spatial heterogeneity by allowing the sensitivity to exogenous variables to vary across land owners.

The paper addresses the well recognized econometric challenge of estimating spatial discrete choice models with medium-to-large sized sample by using a composite marginal likelihood (CML) inference approach in estimation. The CML approach can be applied to data sets of any size and does not require any simulation machinery. To evaluate the ability of the CML approach to recover model parameters in a spatial-temporal context, we undertake a simulation exercise. The results indicate that the CML approach recovers the parameters reasonably well. In addition, the simulation study demonstrates that ignoring spatial dependency and spatial heterogeneity when both are actually present will introduce substantial bias. Further, 
there is a suggestion in the result that ignoring spatial heterogeneity is of much more serious consequence than ignoring spatial lag dynamics.

The model system proposed in the current paper is applied in a demonstration exercise to examine urban land development intensity levels using parcel-level data from Austin, Texas. These results reinforce the findings from the simulation exercise, and indicate the potentially substantial biases in elasticity effects if spatial dependence and/or heterogeneity are ignored. Future efforts need to continue to undertake simulation experiments to evaluate the performance of the composite marginal likelihood approach for estimating models with spatial and temporal dependence (for example, with varying sample sizes, varying levels of dependence, and larger number of data repetitions), and on application of this inference approach for spatial discrete choice modeling.

\section{ACKNOWLEDGEMENTS}

This research was partially funded by a Southwest Region University Transportation Center grant. The authors are grateful to Lisa Macias for her help in formatting this document. Two anonymous referees provided valuable comments on an earlier version of this paper. 


\section{REFERENCES}

Anselin L (2010) Thirty years of spatial econometrics. Papers in Regional Science 89(1): 3-25.

Anselin L, Gallo JL, Jayet H (2008) Spatial panel econometrics. In: Mátyás L, Sevestre P (eds) The Econometrics of Panel Data: Fundamentals and Recent Developments in Theory and Practice, Springer, New York, 46, pp 625-660.

Arbia G, Kelejian H (2010) Advances in spatial econometrics. Regional Science and Urban Economics 40(5): 253-254.

Beron KJ, Vijverberg WPM (2004) Probit in a spatial context: A Monte Carlo analysis. In: Anselin L, Florax RJGM, Rey SJ (eds) Advances in Spatial Econometrics: Methodology, Tools and Applications, Springer, New York, pp 169-195.

Beron KJ, Murdoch JC, Vijverberg WPM (2003) Why cooperate? Public goods, economic power, and the Montreal Protocol. Review of Economics and Statistics 85(2): 86-97.

Bhat CR (2011) The maximum approximate composite marginal likelihood (MACML) estimation of multinomial probit-based unordered response choice models. Transportation Research Part B 45(7): 923-939.

Bhat CR, Sener IN (2009) A copula-based closed-form binary logit choice model for accommodating spatial correlation across observational units. Journal of Geographical Systems 11(3): 243-272.

Bhat CR, Sener IN, Eluru N (2010a) A flexible spatially dependent discrete choice model: Formulation and application to teenagers' weekday recreational activity participation. Transportation Research Part B 44(8-9): 903-921.

Bhat CR, Varin C, Ferdous N (2010b) A comparison of the maximum simulated likelihood and composite marginal likelihood estimation approaches in the context of the multivariate ordered response model. In: Greene W, Hill RC (eds) Advances in Econometrics: Maximum Simulated Likelihood Methods and Applications, Emerald Group Publishing Limited, 26, pp 65-106.

Brady M., Irwin E (2011) Accounting for spatial effects in economic models of land use: Recent developments and challenges ahead. Environmental and Resource Economics 48(4): 487509.

CACOG (2011) Geospatial data. Available at: http://www.capcog.org/data-maps-andreports/geospatial-data/.

Carrión-Flores C, Irwin EG (2004) Determinants of residential land-use conversion and sprawl at the rural-urban fringe. American Journal of Agricultural Economics 86(4): 889-904.

Carrión-Flores CE, Flores-Lagunes A, Guci L (2009) Land use change: A spatial multinomial choice analysis. Paper prepared for presentation at the III World Conference of Spatial Econometrics, Barcelona, Spain.

Chakir R, Parent O (2009) Determinants of land use changes: A spatial multinomial probit approach. Papers in Regional Science 88(2): 327-344.

City of Austin (2011) City of Austin GIS data sets. Available at: ftp://ftp.ci.austin.tx.us/GISData/Regional/coa_gis.html\#base_map. 
Elhorst JP (2009) Spatial panel data models. In: Fischer MM, Getis A (eds) Handbook of Applied Spatial Analysis, Springer, Berlin, pp 377-408.

Ferdous N, Eluru N, Bhat CR, Meloni I (2010) A multivariate ordered response model system for adults' weekday activity episode generation by activity purpose and social context. Transportation Research Part B 44(8-9): 922-943.

Franzese RJ, Hays JC (2008) Empirical models of spatial interdependence. In: BoxSteffensmeier J, Brady H, Collier D (eds) Oxford Handbook of Political Methodology, Oxford University Press, pp 570-604.

Franzese RJ, Hays JC, Schaffer LM (2010) Spatial, temporal, and spatiotemporal autoregressive probit models of binary outcomes: Estimation, interpretation, and presentation. APSA 2010 Annual Meeting Paper. Available at SSRN: http://ssrn.com/abstract=1643867.

Geoghegan J (2002) The value of open spaces in residential land use. Land Use Policy 19(1): 9198.

Greene WH, Hensher DA (2010) Modeling Ordered Choices: A Primer. Cambridge University Press, Cambridge.

Irwin EG, Bockstael NE (2002) Interacting agents, spatial externalities and the evolution of residential land use patterns. Journal of Economic Geography 2(1): 31-54.

Kakamu K, Wago H (2007) Bayesian spatial panel probit model with an application to business cycle in Japan. Working paper.

Available at: http://www.mssanz.org.au/modsim05/proceedings/papers/kakamu_2.pdf.

Lee L-F, Yu J (2010) Estimation of spatial autoregressive panel data models with fixed effects. Journal of Econometrics 154(2): 165-185.

LeSage JP, Pace RK (2009) Introduction to spatial econometrics. Chapman \& Hall/CRC, Taylor \& Francis Group, Boca Raton.

Li X, Liu XP (2007) Defining agents' behaviors to simulate complex residential development using multicriteria evaluation. Journal of Environmental Management 85(4): 1063-1075.

Luechinger S, Stutzer A, Winkelmann R (2010) Self-selection models for public and private sector job satisfaction. In: Polachek SW, Tatsiramos K (eds) Research in Labor Economics, Emerald Group Publishing Limited, 30, pp 233-251.

McKelvey RD, Zavoina W (1975) A statistical model for the analysis of ordinal-level dependent variables. Journal of Mathematical Sociology 4: 103-120.

Müller G, Czado C (2005) An autoregressive ordered probit model with application to high frequency financial data. Journal of Computational and Graphical Statistics 14(2): 320-338.

Pace L, Salvan A, Sartori N (2011) Adjusting composite likelihood ratio statistics. Statistica Sinica 21(1): 129-148.

Quddus MA, Wang C, Ison SG (2010) Road traffic congestion and crash severity: Econometric analysis using ordered response models. Journal of Transportation Engineering 136(5): 424435. 
Roorda MJ, Paez A, Morency C, Mercado R, Farber S (2010) Trip generation of vulnerable populations in three Canadian cities: A spatial ordered probit approach. Transportation 37(3): 525-548.

Smirnov OA (2010) Spatial econometrics approach to integration of behavioral biases in travel demand analysis. Transportation Research Record 2157: 1-10.

Varin C, Czado C (2010) A mixed autoregressive probit model for ordinal longitudinal data. Biostatistics 11(1): 127-138.

Varin, C., Vidoni P (2005) A note on composite likelihood inference and model selection. Biometrika 92(3): 519-528.

Varin C, Vidoni P (2009) Pairwise likelihood inference for general state space models. Econometric Reviews 28(1-3): 170-185.

Xiong W (2011) Measuring the monetary policy stance of the People's Bank of China: An ordered probit analysis. China Economic Review, forthcoming.

Yi GY, Zeng L, Cook RJ (2011) A robust pairwise likelihood method for incomplete longitudinal binary data arising in clusters. Canadian Journal of Statistics 39(1): 34-51. 
Table 1a Ability of the CML Approach to Recover the Parameters of the Spatial Panel Ordered-Response Model - The Low Spatial Autoregressive Coefficient Case

\begin{tabular}{|c|c|c|c|c|c|c|c|c|}
\hline \multirow{3}{*}{ Parameter } & \multicolumn{4}{|c|}{ Low temporal autoregressive coefficient $(\rho=0.25)$} & \multicolumn{4}{|c|}{ High temporal autoregressive coefficient $(\rho=0.75)$} \\
\hline & \multirow[b]{2}{*}{ True Value } & \multicolumn{2}{|c|}{ Parameter Estimates } & \multirow[b]{2}{*}{$\begin{array}{l}\text { Asymptotic } \\
\text { Standard } \\
\text { Error (ASE) }\end{array}$} & \multirow[b]{2}{*}{ True Value } & \multicolumn{2}{|c|}{ Parameter Estimates } & \multirow[b]{2}{*}{$\begin{array}{l}\text { Asymptotic } \\
\text { Standard } \\
\text { Error (ASE) }\end{array}$} \\
\hline & & $\begin{array}{c}\text { Mean } \\
\text { Estimate }\end{array}$ & $\begin{array}{c}\text { Absolute } \\
\text { Percentage } \\
\text { Bias (APB) } \\
\end{array}$ & & & $\begin{array}{c}\text { Mean } \\
\text { Estimate }\end{array}$ & $\begin{array}{c}\text { Absolute } \\
\text { Percentage } \\
\text { Bias (APB) } \\
\end{array}$ & \\
\hline$b_{1}$ & 0.5000 & 0.4986 & 0.28 & 0.0056 & 0.5000 & 0.5075 & 1.49 & 0.0055 \\
\hline$b_{2}$ & 0.8000 & 0.7942 & 0.73 & 0.0100 & 0.8000 & 0.8124 & 1.55 & 0.0103 \\
\hline$b_{3}$ & 1.0000 & 1.0161 & 1.61 & 0.0113 & 1.0000 & 1.0767 & 7.67 & 0.0119 \\
\hline$\psi_{1}$ & -1.0000 & -1.0622 & 6.22 & 0.0104 & -1.0000 & -1.0217 & 2.17 & 0.0100 \\
\hline$\psi_{2}$ & 1.0000 & 1.0116 & 1.16 & 0.0110 & 1.0000 & 1.0320 & 3.20 & 0.0117 \\
\hline$\sigma_{22}$ & 1.0000 & 1.0397 & 3.97 & 0.0183 & 1.0000 & 0.9734 & 2.66 & 0.0180 \\
\hline$\sigma_{33}$ & 1.0000 & 0.9406 & 5.94 & 0.0182 & 1.0000 & 0.9479 & 5.21 & 0.0180 \\
\hline$\delta$ & 0.2500 & 0.2514 & 0.58 & 0.0200 & 0.2500 & 0.2586 & 3.45 & 0.0212 \\
\hline$\rho$ & 0.2500 & 0.2501 & 0.03 & 0.0222 & 0.7500 & 0.7507 & 0.09 & 0.0053 \\
\hline \multicolumn{3}{|c|}{$\begin{array}{l}\text { Overall mean value across } \\
\text { parameters }\end{array}$} & 2.28 & 0.0141 & - & - & 3.06 & 0.0124 \\
\hline
\end{tabular}

Table 1b Ability of the CML Approach to Recover the Parameters of the Spatial Panel Ordered-Response Model - The High Spatial Autoregressive Coefficient Case

\begin{tabular}{|c|c|c|c|c|c|c|c|c|}
\hline \multirow{3}{*}{ Parameter } & \multicolumn{4}{|c|}{ Low temporal autoregressive coefficient $(\rho=0.25)$} & \multicolumn{4}{|c|}{ High temporal autoregressive coefficient $(\rho=0.75)$} \\
\hline & \multirow[b]{2}{*}{ True Value } & \multicolumn{2}{|c|}{ Parameter Estimates } & \multirow[b]{2}{*}{$\begin{array}{c}\text { Asymptotic } \\
\text { Standard } \\
\text { Error (ASE) }\end{array}$} & \multirow[b]{2}{*}{ True Value } & \multicolumn{2}{|c|}{ Parameter Estimates } & \multirow[b]{2}{*}{$\begin{array}{l}\text { Asymptotic } \\
\text { Standard } \\
\text { Error (ASE) }\end{array}$} \\
\hline & & $\begin{array}{c}\text { Mean } \\
\text { Estimate }\end{array}$ & $\begin{array}{c}\text { Absolute } \\
\text { Percentage } \\
\text { Bias (APB) }\end{array}$ & & & $\begin{array}{c}\text { Mean } \\
\text { Estimate }\end{array}$ & $\begin{array}{c}\text { Absolute } \\
\text { Percentage } \\
\text { Bias (APB) }\end{array}$ & \\
\hline$b_{1}$ & 0.5000 & 0.4780 & 4.40 & 0.0058 & 0.5000 & 0.4978 & 0.43 & 0.0065 \\
\hline$b_{2}$ & 0.8000 & 0.8354 & 4.43 & 0.0103 & 0.8000 & 0.8270 & 3.37 & 0.0117 \\
\hline$b_{3}$ & 1.0000 & 1.0528 & 5.28 & 0.0121 & 1.0000 & 1.0975 & 9.75 & 0.0143 \\
\hline$\psi_{1}$ & -1.0000 & -1.0757 & 7.57 & 0.0123 & -1.0000 & -1.1374 & 13.74 & 0.0142 \\
\hline$\psi_{2}$ & 1.0000 & 1.0250 & 2.50 & 0.0119 & 1.0000 & 0.9945 & 0.55 & 0.0125 \\
\hline$\sigma_{22}$ & 1.0000 & 0.9499 & 5.01 & 0.0179 & 1.0000 & 0.8710 & 12.90 & 0.0326 \\
\hline$\sigma_{33}$ & 1.0000 & 0.9444 & 5.56 & 0.0168 & 1.0000 & 0.9115 & 8.85 & 0.0202 \\
\hline$\delta$ & 0.7500 & 0.6929 & 7.62 & 0.0034 & 0.7500 & 0.6739 & 10.14 & 0.0034 \\
\hline$\rho$ & 0.2500 & 0.2422 & 3.12 & 0.0087 & 0.7500 & 0.7339 & 2.15 & 0.0103 \\
\hline \multicolumn{3}{|c|}{$\begin{array}{l}\text { Overall mean value across } \\
\text { parameters }\end{array}$} & 5.05 & 0.0110 & - & - & 6.88 & 0.0140 \\
\hline
\end{tabular}


Table 2 Effects of Ignoring Spatial Effects When Present

\begin{tabular}{|c|c|c|c|c|c|c|c|c|c|c|c|c|}
\hline \multirow{2}{*}{$\begin{array}{l}\text { Evaluation } \\
\text { Metric }\end{array}$} & \multicolumn{3}{|c|}{$\delta=0.25, \rho=0.25$} & \multicolumn{3}{|c|}{$\delta=0.25, \rho=0.75$} & \multicolumn{3}{|c|}{$\delta=0.75, \rho=0.25$} & \multicolumn{3}{|c|}{$\delta=0.75, \rho=0.75$} \\
\hline & $\begin{array}{l}\text { ORSH } \\
\text { Model }\end{array}$ & $\begin{array}{c}\text { ORH } \\
\text { Model }\end{array}$ & ORS Model & $\begin{array}{l}\text { ORSH } \\
\text { Model }\end{array}$ & $\begin{array}{c}\text { ORH } \\
\text { Model }\end{array}$ & $\begin{array}{c}\text { ORS } \\
\text { Model }\end{array}$ & $\begin{array}{l}\text { ORSH } \\
\text { Model }\end{array}$ & $\begin{array}{c}\text { ORH } \\
\text { Model }\end{array}$ & ORS Model & $\begin{array}{l}\text { ORSH } \\
\text { Model }\end{array}$ & $\begin{array}{c}\text { ORH } \\
\text { Model }\end{array}$ & ORS Model \\
\hline \begin{tabular}{|l||} 
Mean APB \\
For comparison \\
of ORSH model \\
with ORH \\
model
\end{tabular} & 2.49 & 3.07 & - & 3.01 & 3.07 & - & 4.73 & 16.14 & - & 6.47 & 17.53 & - \\
\hline $\begin{array}{l}\text { For comparison } \\
\text { of ORSH model } \\
\text { with ORS } \\
\text { model }\end{array}$ & 1.51 & - & 35.14 & 2.80 & - & 29.09 & 4.99 & - & 27.61 & 5.73 & - & 29.14 \\
\hline $\begin{array}{l}\text { Mean composite } \\
\text { log-likelihood } \\
\text { value at } \\
\text { convergence }\end{array}$ & $-135,448$ & $-135,522$ & $-139,956$ & $-133,954$ & $-134,050$ & $-138,155$ & $-133,275$ & $-134,792$ & $-136,781$ & $-132,667$ & $-134,143$ & $-136,948$ \\
\hline $\begin{array}{l}\text { Number of times } \\
\text { the adjusted } \\
\text { composite } \\
\text { likelihood ratio } \\
\text { test (ADCLRT) } \\
\text { statistic favors } \\
\text { the ORSH model }\end{array}$ & - & $\begin{array}{c}\text { All twenty } \\
\text { times when } \\
\text { compared } \\
\text { with } \\
\chi_{1}^{2}=3.84 \\
\text { value } \\
\text { (mean } \\
\text { ADCLRT } \\
\text { statistic is } \\
97.80 \text { ) }\end{array}$ & $\begin{array}{c}\text { All twenty } \\
\text { times when } \\
\text { compared } \\
\text { with } \\
\chi_{2}^{2}=5.99 \\
\text { value (mean } \\
\text { ADCLRT } \\
\text { statistic is } \\
6,693.97 \text { ) }\end{array}$ & - & $\begin{array}{c}\text { All twenty } \\
\text { times when } \\
\text { compared } \\
\text { with } \\
\chi_{1}^{2}=3.84 \\
\text { value (mean } \\
\text { ADCLRT } \\
\text { statistic is } \\
139.38 \text { ) }\end{array}$ & $\begin{array}{c}\text { All twenty } \\
\text { times when } \\
\text { compared } \\
\text { with } \\
\chi_{2}^{2}=5.99 \\
\text { value (mean } \\
\text { ADCLRT } \\
\text { statistic is } \\
5,834.31 \text { ) }\end{array}$ & - & $\begin{array}{l}\text { All twenty } \\
\text { times when } \\
\text { compared } \\
\text { with } \\
\chi_{1}^{2}=3.84 \\
\text { value (mean } \\
\text { ADCLRT } \\
\text { statistic is } \\
2,173.70 \text { ) }\end{array}$ & $\begin{array}{c}\text { All fifteen } \\
\text { times when } \\
\text { compared } \\
\text { with } \\
\chi_{2}^{2}=5.99 \\
\text { value (mean } \\
\text { ADCLRT } \\
\text { statistic is } \\
6,395.06 \text { ) }\end{array}$ & - & $\begin{array}{c}\text { All twenty } \\
\text { times when } \\
\text { compared } \\
\text { with } \\
\chi_{1}^{2}=3.84 \\
\text { value } \\
\text { (mean } \\
\text { ADCLRT } \\
\text { statistic is } \\
2,073.70 \text { ) }\end{array}$ & $\begin{array}{l}\text { All eighteen } \\
\text { times when } \\
\text { compared } \\
\text { with } \\
\chi_{2}^{2}=5.99 \\
\text { value (mean } \\
\text { ADCLRT } \\
\text { statistic is } \\
4,862.69 \text { ) }\end{array}$ \\
\hline
\end{tabular}


Table 3 Number (Percentage) of Parcels by Land Use Development Intensity (LUDI) Level and Year of Observation

\begin{tabular}{|c|c|c|c|c|}
\hline \multirow{2}{*}{ Land Use Development Intensity (LUDI) Level } & \multicolumn{4}{|c|}{ Year of Observation } \\
\hline & 2000 & 2003 & 2006 & 2008 \\
\hline $\begin{array}{l}\text { Undeveloped land (includes open space, rural area, agricultural } \\
\text { land, and vacant parcels) }\end{array}$ & $\begin{array}{c}285 \\
(36.4)\end{array}$ & $\begin{array}{c}290 \\
(37.0)\end{array}$ & $\begin{array}{c}98 \\
(12.5)\end{array}$ & $\begin{array}{c}80 \\
(10.2)\end{array}$ \\
\hline $\begin{array}{l}\text { Low intensity developed land (includes residential parcels with } \\
\text { single-family detached and two-family attached homes) }\end{array}$ & $\begin{array}{c}469 \\
(59.9)\end{array}$ & $\begin{array}{c}450 \\
(57.5)\end{array}$ & $\begin{array}{c}642 \\
(82.0)\end{array}$ & $\begin{array}{c}660 \\
(84.3)\end{array}$ \\
\hline $\begin{array}{l}\text { Medium intensity developed land (includes all other residential } \\
\text { parcels such as apartment, condo, three/fourplex, group } \\
\text { quarters, and retirement homes) }\end{array}$ & $\begin{array}{c}14 \\
(1.8)\end{array}$ & $\begin{array}{c}26 \\
(3.3)\end{array}$ & $\begin{array}{c}22 \\
(2.8)\end{array}$ & $\begin{array}{c}22 \\
(2.8)\end{array}$ \\
\hline $\begin{array}{l}\text { High intensity developed land (includes parcels developed for } \\
\text { office, commercial, or industrial use) }\end{array}$ & $\begin{array}{l}15 \\
(1.9)\end{array}$ & $\begin{array}{c}17 \\
(2.2)\end{array}$ & $\begin{array}{l}21 \\
(2.7)\end{array}$ & $\begin{array}{l}21 \\
(2.7)\end{array}$ \\
\hline Total number of parcels & 783 & 783 & 783 & 783 \\
\hline
\end{tabular}

Table 4 Model Selection Based on the Weight Matrix Specification

\begin{tabular}{||l||c|c|c||}
\hline \multicolumn{1}{||c||}{} & \multicolumn{3}{c||}{ Weight Matrix Specification } \\
\cline { 2 - 4 } & Contiguity & $\begin{array}{c}\text { Inverse of } \\
\text { continuous distance } \\
\mathbf{( 0 . 2 5} \text { mile distance } \\
\text { band) }\end{array}$ & $\begin{array}{c}\text { Inverse of } \\
\text { continuous distance } \\
\text { square (0.25 mile } \\
\text { distance band) }\end{array}$ \\
\hline \hline Log-composite likelihood at convergence & -724619.52 & -718753.28 & -720435.17 \\
Trace value & 1780.35 & 1343.63 & 2338.49 \\
CLIC statistic & -726399.87 & -720096.92 & -722773.66 \\
\hline \hline
\end{tabular}


Table 5 Model Estimation Results (Weight Matrix: inverse of distance, Distance Band 0.25 miles)

\begin{tabular}{|c|c|c|c|c|}
\hline & \multicolumn{2}{|c|}{$\begin{array}{c}\text { Parameter - Mean } \\
\text { Estimate }\end{array}$} & \multicolumn{2}{|c|}{$\begin{array}{l}\text { Parameter - Standard } \\
\text { Deviation Estimate }\end{array}$} \\
\hline & Estimate & t-stat & Estimate & t-stat \\
\hline Constant & 0.000 & - & 0.006 & 4.25 \\
\hline \multicolumn{5}{|l|}{ Closeness to natural amenities, school, and the CBD } \\
\hline Distance to a park $\leq 2$ miles (base: park $>2$ miles) & 0.112 & 1.21 & - & - \\
\hline Distance to a lake $\leq 5$ miles (base: lake $>5$ miles) & 0.623 & 5.38 & 1.301 & 8.38 \\
\hline Distance to a school $\leq 2$ miles (base: school $>2$ miles) & 0.044 & 1.19 & - & - \\
\hline Distance to the downtown area $\leq 9$ miles (base: downtown $>9$ miles) & -0.203 & -1.56 & - & - \\
\hline \multicolumn{5}{|l|}{ Ease of access to the transportation system } \\
\hline Distance to IH-35 $\leq 9$ miles (base: IH-35 $>9$ miles) & 0.322 & 5.15 & - & - \\
\hline Distance to a public airfield $\leq 1$ miles (base: airfield $>1$ miles) & -0.224 & -2.44 & 0.355 & 1.91 \\
\hline \multicolumn{5}{|l|}{ Year-specific dummy variables and other variables } \\
\hline Year 2006 (base: Years 2000/2003) & 0.136 & 4.08 & - & - \\
\hline Year 2008 & 0.147 & 4.36 & - & - \\
\hline Parcel is located in Austin city (base: parcel is located outside Austin city) & -0.807 & -4.88 & - & - \\
\hline Average elevation of parcel $\leq 1000$ feet above mean sea level (base: average elevation $>1000$ feet) & -0.242 & -3.39 & - & - \\
\hline \multicolumn{5}{|l|}{ Auto-regressive parameters ${ }^{*}$} \\
\hline Spatial auto-regressive co-efficient $(\delta)$ & 0.905 & 50.49 & - & - \\
\hline Temporal auto-regressive co-efficient $(\rho)$ & 0.344 & 1.59 & - & - \\
\hline \multicolumn{5}{|l|}{ Thresholds } \\
\hline$\psi_{1}$ & -5.438 & -6.66 & - & - \\
\hline$\psi_{2}$ & -1.850 & -6.77 & - & - \\
\hline$\psi_{3}$ & -1.267 & -6.14 & - & - \\
\hline
\end{tabular}

* Standard errors of the auto-regressive parameters are estimated using the delta method. 
Table 6 Elasticity Effects of Variables on the Land Use Development Intensity Level (Standard Error)*

\begin{tabular}{|c|c|c|c|c|c|c|c|c|c|c|c|c|}
\hline \multirow{2}{*}{ Variable } & \multicolumn{3}{|c|}{ Undeveloped land } & \multicolumn{3}{|c|}{$\begin{array}{l}\text { Less-intensely } \\
\text { developed land }\end{array}$} & \multicolumn{3}{|c|}{$\begin{array}{l}\text { Medium-intensely } \\
\text { developed land }\end{array}$} & \multicolumn{3}{|c|}{$\begin{array}{l}\text { Most-intensely } \\
\text { developed land }\end{array}$} \\
\hline & $\begin{array}{l}\text { ORSH } \\
\text { model }\end{array}$ & $\begin{array}{c}\text { OR } \\
\text { model }\end{array}$ & \begin{tabular}{|c|}
-value \\
for \\
difference
\end{tabular} & $\begin{array}{l}\text { ORSH } \\
\text { model }\end{array}$ & $\begin{array}{c}\text { OR } \\
\text { model }\end{array}$ & \begin{tabular}{|c|} 
p-value \\
for \\
difference
\end{tabular} & $\begin{array}{l}\text { ORSH } \\
\text { model }\end{array}$ & $\begin{array}{c}\text { OR } \\
\text { model }\end{array}$ & $\begin{array}{c}\text { p-value } \\
\text { for } \\
\text { difference }\end{array}$ & $\begin{array}{l}\text { ORSH } \\
\text { model }\end{array}$ & $\begin{array}{c}\text { OR } \\
\text { model }\end{array}$ & $\begin{array}{c}\text { p-value } \\
\text { for } \\
\text { difference }\end{array}$ \\
\hline $\begin{array}{l}\text { Distance to a park } \leq 2 \text { miles } \\
\text { (base: } \text { park }>2 \text { miles) }\end{array}$ & $\begin{array}{r}-20.96 \\
(4.96)\end{array}$ & $\begin{array}{c}-4.89 \\
(12.55)\end{array}$ & - & $\begin{array}{l}-4.78 \\
(4.44)\end{array}$ & $\begin{array}{l}-0.17 \\
(0.61)\end{array}$ & - & $\begin{array}{c}30.64 \\
(16.85)\end{array}$ & $\begin{array}{c}3.61 \\
(8.92)\end{array}$ & 0.157 & $\begin{array}{c}56.65 \\
(19.40)\end{array}$ & $\begin{array}{c}3.97 \\
(14.55)\end{array}$ & 0.030 \\
\hline $\begin{array}{l}\text { Distance to a lake } \leq 5 \text { miles } \\
\text { (base: lake }>5 \text { miles) }\end{array}$ & $\begin{array}{r}-79.10 \\
(6.12)\end{array}$ & $\begin{array}{r}-67.37 \\
(6.12)\end{array}$ & 0.176 & \begin{tabular}{|c}
-79.25 \\
$(3.86)$
\end{tabular} & $\begin{array}{l}-7.87 \\
(3.15)\end{array}$ & 0.000 & $\begin{array}{l}-25.47 \\
(68.61)\end{array}$ & $\begin{array}{c}80.66 \\
(10.49)\end{array}$ & 0.127 & $\begin{array}{l}167.64 \\
(15.73)\end{array}$ & $\begin{array}{l}148.36 \\
(21.05)\end{array}$ & - \\
\hline $\begin{array}{l}\text { Distance to a school } \leq 2 \text { miles } \\
\text { (base: } \text { school }>2 \text { miles) }\end{array}$ & $\begin{array}{l}-56.05 \\
(26.43)\end{array}$ & $\begin{array}{l}-10.44 \\
(10.54)\end{array}$ & 0.110 & $\begin{array}{c}3.29 \\
(3.90)\end{array}$ & $\begin{array}{c}0.00 \\
(0.46)\end{array}$ & - & $\begin{array}{l}10.38 \\
(2.41)\end{array}$ & $\begin{array}{c}6.25 \\
(7.01)\end{array}$ & - & $\begin{array}{c}8.05 \\
(3.17)\end{array}$ & $\begin{array}{c}6.9 \\
(11.33)\end{array}$ & - \\
\hline $\begin{array}{l}\text { Downtown } \leq 9 \text { miles } \\
(\text { base: Downtown }>9 \text { miles) }\end{array}$ & $\begin{array}{c}68.54 \\
(18.17)\end{array}$ & $\begin{array}{c}41.32 \\
(10.72)\end{array}$ & 0.198 & $\begin{array}{c}3.10 \\
(11.67)\end{array}$ & $\begin{array}{c}0.29 \\
(1.39)\end{array}$ & - & $\begin{array}{l}-58.03 \\
(13.38)\end{array}$ & $\begin{array}{r}-29.85 \\
(8.14)\end{array}$ & 0.073 & $\begin{array}{r}-67.17 \\
(7.57)\end{array}$ & $\begin{array}{r}-42.39 \\
(9.70)\end{array}$ & 0.045 \\
\hline $\begin{array}{l}\text { IH-35 } \leq 9 \text { miles } \\
\text { (base: } \text { IH-35 }>9 \text { miles) }\end{array}$ & $\begin{aligned}-173.26 \\
(97.81)\end{aligned}$ & $\begin{array}{l}-4.62 \\
(9.40)\end{array}$ & 0.087 & $\begin{array}{c}7.96 \\
(7.72)\end{array}$ & $\begin{array}{l}-0.07 \\
(0.4)\end{array}$ & - & $\begin{array}{l}31.52 \\
(5.47)\end{array}$ & $\begin{array}{c}3.31 \\
(7.08)\end{array}$ & 0.002 & $\begin{array}{l}40.62 \\
(3.62)\end{array}$ & $\begin{array}{c}3.86 \\
(10.72)\end{array}$ & 0.001 \\
\hline $\begin{array}{l}\text { Airfield } \leq 1 \text { miles } \\
(\text { base: Airfield }>1 \text { miles) }\end{array}$ & $\begin{array}{l}57.73 \\
(7.42)\end{array}$ & $\begin{array}{l}30.95 \\
(6.50)\end{array}$ & 0.007 & $\begin{array}{c}8.06 \\
(10.65)\end{array}$ & $\begin{array}{c}1.11 \\
(1.05)\end{array}$ & - & $\begin{array}{l}-77.99 \\
(38.30)\end{array}$ & $\begin{array}{r}-29.17 \\
(7.14)\end{array}$ & - & $\begin{array}{r}-108.92 \\
(40.98)\end{array}$ & $\begin{array}{r}-38.32 \\
(9.83)\end{array}$ & 0.094 \\
\hline $\begin{array}{l}\text { Parcel is located in Austin city } \\
\text { (base: parcel is located outside Austin city) }\end{array}$ & $\begin{array}{l}216.30 \\
(41.12)\end{array}$ & $\begin{array}{r}129.93 \\
(9.54)\end{array}$ & 0.041 & $\begin{array}{c}-4.25 \\
(26.77)\end{array}$ & $\begin{array}{c}0.69 \\
(4.50)\end{array}$ & - & $\begin{array}{r}-105.35 \\
(12.63)\end{array}$ & $\begin{array}{r}-96.79 \\
(6.57)\end{array}$ & - & $\begin{array}{r}-108.09 \\
(6.76)\end{array}$ & $\begin{array}{r}-121.62 \\
(6.46)\end{array}$ & 0.148 \\
\hline $\begin{array}{l}\text { Elevation } \leq 1000 \text { feet above mean sea level } \\
\text { (base: elevation }>1000 \text { feet) }\end{array}$ & $\begin{array}{l}120.97 \\
(49.74)\end{array}$ & $\begin{array}{l}32.52 \\
(6.62)\end{array}$ & 0.079 & $\begin{array}{c}-2.06 \\
(13.14)\end{array}$ & $\begin{array}{c}0.53 \\
(1.09)\end{array}$ & - & $\begin{array}{r}-54.95 \\
(9.15)\end{array}$ & $\begin{array}{r}-24.19 \\
(4.35)\end{array}$ & 0.003 & $\begin{array}{r}-58.86 \\
(4.41)\end{array}$ & $\begin{array}{r}-36.00 \\
(5.92)\end{array}$ & 0.002 \\
\hline
\end{tabular}

* The standard errors of the elasticity effects are computed using 100 bootstrap draws. A "_" entry in the table indicates that the difference is not statistically significant even at the 0.20 level of significance. 